\title{
Het kerke 'n publieke rol in 'n pluralistiese Suid-Afrika?
}

\author{
Author: \\ Willem Fourie ${ }^{1}$ \\ Affiliation: \\ ${ }^{1}$ Department Dogmatics and \\ Christian Ethics, University of \\ Pretoria, South Africa \\ Correspondence to: \\ Willem Fourie \\ Email: \\ willem.fourie@up.ac.za \\ Postal address: \\ Private Bag X20, Hatfield, \\ Pretoria 0028, South Africa \\ Dates: \\ Received: 17 Feb. 2011 \\ Accepted: 14 Apr. 2011 \\ Published: 28 July 2011 \\ How to cite this article: \\ Fourie, W., 2011, 'Het \\ kerke 'n publieke rol in 'n \\ pluralistiese Suid-Afrika?', \\ Verbum et Ecclesia 32(1), Art. \\ \#503, 6 pages. doi:10.4102/ \\ ve.v32i1.503
}

(C) 2011. The Authors. Licensee: OpenJournals Publishing. This work is licensed under the Creative Commons Attribution License.

\section{Churches' public role in a pluralistic South Africa}

South Africa's diversity provides significant challenges to public involvement by churches. In some circles it is even believed that this diversity disqualifies churches from any form of public involvement. This diversity is protected by a liberal constitution and nurturing it is one of the explicit aims of the South African consolidating democracy. The German theologians Michael Welker and Wolfgang Huber typify the diversity of democratic societies as 'pluralism'. In this article, both theologians' conceptualisation of 'pluralism' was considered and used to set conditions for the South African churches' public involvement.

\section{Inleiding}

Verskeidenheid is waarskynlik een van die definiërende kenmerke van die Suid-Afrikaanse samelewing. Die beskrywing van hierdie verskeidenheid het 'n digte, in sommige opsigte weersprekende, geskiedenis. Tydens die begrafnis van Chris Hani in 1993, tipeer aartsbiskop Desmond Tutu hierdie verskeidenheid byvoorbeeld op 'n versoenende wyse as dié van God se reënboogmense (vlg. Tutu 1996). In sy inhuldigingstoespraak op 10 Mei 1994 ontwikkel oudpresident Nelson Mandela (1994) hierdie metafoor verder om beide die unieke menswaardigheid van alle Suid-Afrikaners en 'n geïntegreerde samelewing te beskryf:

'We have triumphed in the effort to implant hope in the breasts of the millions of our people. We enter into a covenant that we shall build the society in which all South Africans, both black and white, will be able to walk tall, without any fear in their hearts, assured of their inalienable right to human dignity - a rainbow nation at peace with itself and the world'.

[Ons het oorwin in die poging om hoop in die bors van miljoene van ons mense te plant. Ons tree in ' $n$ verbond dat ons die samelewing sal bou waarin alle Suid-Afrikaners, beide Swart en Wit, regop sal kan loop, sonder enige vrees in hulle harte, verseker van hulle onvervreembare reg tot menswaardigheid - ' $n$ reënboognasie in vrede met ditself en die wêreld.]

(Mandela 1994)

Die konsep 'reënboognasie' is natuurlik slegs een van die vele pogings om die verskeidenheid van die Suid-Afrikaanse samelewing te beskryf. Die steeds groeiende aantal konsepte het baie te make met die verskeidenheid van verskeidenhede en onderlinge verbintenisse tussen dié verskeidenhede wat in Suid-Afrika aangetref word. Tutu en Mandela het na alle waarskynlikheid veral na die kulturele verskeidenheid in Suid-Afrika verwys met die konsep 'reënboognasie'. Verwante begrippe is in dié verband die soeke na 'nasionale eenheid' (vgl. Deng 2010; Gutteridge 1995) of selfs 'sosiale kohesie' (vlg. Chidester, Dexter \& James 2003). Suid-Afrika se kulturele verskeidenheid is steeds nou verbind aan die samelewing se problematiese ekonomiese verskeidenheid. Hierdie verskeidenheid word weer veral in terme van die konsep 'ongelykheid' getematiseer (vlg. Seekings \& Nattrass 2006; en die ietwat polemiese Terreblanche 2002) en word ten nouste met regeringsbeleid verbind (vgl. Aron, Kahn \& Kingdon 2009; Bhorat \& Kanbur 2006). Naas hierdie twee vorme van verskeidenheid is daar natuurlik ook menigte ander vorme, waaronder linguïstiese, religieuse, geslags- of gender- en politieke verskeidenheid.

Die oorgang na 'n konstitusionele demokrasie in 1994 en die aanvaarding van Suid-Afrika se progressiewe grondwet in 1996 het dié faktiese verskeidenheid geïnstitusionaliseer. Spesifiek die Handves van Regte (hoofstuk 2) beskerm en bevorder 'n robuuste samelewingsverskeidenheid. Die Handves word beskou as die 'hoeksteen van die demokrasie in Suid-Afrika' - Art. 7(1) - wat die 'volle en gelyke genieting van alle regte en vryhede' van alle Suid-Afrikaners beskerm in terme van Art. 9(2). Dit sluit die vryhede van godsdiens, oortuiging en mening (Art. 15), van uitdrukking (Art. 16), van assosiasie (Art. 18) en die reg om kultuur-, godsdiens- en taalgemeenskappe te vorm (Art. 31) in. Ten spyte van soms skeidende vorme van verskeidenheid, verstaan die SuidAfrikaanse samelewing ditself dus as 'n ruimte waar verskeidenheid gekoester moet word.

Vir kerke hou Suid-Afrika se verskeidenheid natuurlik baie spesifieke uitdagings in. Die verskeidenheid van oortuigings binne die publieke sfeer self bied aan kerke die uitdaging om 
hul rol en die inhoud van hul bydrae te oorweeg. Debatte in kerklike en akademiese kringe rondom ' $n$ konsep soos die Suid-Afrikaanse weergawe van 'postmodernisme' is tekenend hiervan (vlg. Du Toit 2000; Koopman \& Vosloo 2002; Niemandt 2007).

In hierdie artikel word gevra of kerke 'n legitieme publieke rol het om te speel te midde van die Suid-Afrikaanse verskeidenhede. Hierdie vraag word beantwoord deur die konsep van 'pluralisme' te gebruik om die geïnstitusionaliseerde verskeidenhede te beskryf. Dit sal gedoen word aan die hand van twee interpretasies van pluralisme, naamlik dié van die Duitse teoloë Michael Welker en Wolfgang Huber. Weens praktiese oorwegings word die bespreking beperk tot 'n oorweging hoofsaaklik vanuit die perspektief van teorieë oor pluralisme.

\section{Welker en pluralisme Pluralisme se magskringloop}

In sy beskrywing van pluralisme herinner Welker ons daaraan dat die betekenis van die begrip geensins voor die hand liggend is nie. Dit verwys na meer as bloot vae verskeidenheid of diversiteit (Welker 1995:13). Dit is 'n komplekse en hoogs-ontwikkelde samelewingvorm wat die konstruktiewe saambestaan van sosiale, kulturele en religieuse verskeidenheid kan moontlik maak (Welker 2002:228) en wat die kwaliteit van verhoudings in 'n samelewing, tussen individue, groepe, instellings en sisteme, wesenlik positief kan beïnvloed (Welker 2000:15).

Welker ontwikkel die konsep 'pluralisme' binne 'n baie spesifieke politieke konteks, naamlik demokrasie. Reeds in Kirche im Pluralismus (1995) stel hy dat die 'kwaliteit van demokratiese politiek en vrye menslike saambestaan' van pluralisme afhang (Welker 1995:15) en dat 'demokratiese politiek' moontlik gemaak word deur 'n samelewing wat die 'voorvereistes vir plurale politieke invloede' beskerm (Welker 1995:16). In 'n ander rigtinggewende artikel oor pluralisme ontwikkel Welker pluralisme as die teelaarde waarbinne die bronne vir politieke lojaliteit in 'n liberale (lees: demokratiese) staat ontwikkel (Welker 2002).

Welker se beskrywing van pluralisme word gekenmerk deur heterogeniteit en dinamiese prosesse van herposisionering. Hy beskryf pluralisme nie in statiese terme nie, maar in terme van die magskringloop daarvan (Welker 1995:13-24; 2002:227-231). Volgens Welker (2002:229vv) word hierdie magskringloop deur twee vorme van veelvoud en hul samespel in stand gehou. Die een vorm noem Welker die assosiasies van die burgerlike samelewing. Assosiasies kan beskryf word as die samekoms van mense met gedeelde doelstellings en gedeelde waardes. Assosiasies is dus direk van die belange van die lede afhanklik en word gekenmerk deur groot onderskeide in aanpasbaarheid tot verandering en lewensduur.

Die ander vorm van veelvoud wat Welker identifiseer, is deelsisteme. Welker verwys hier uitdruklik na Niklas
Luhmann se sisteemteoretiese werk oor Teilsysteme [deelsisteme] (vgl. Luhmann 1982) en integreer elemente van Max Weber se werk oor die Lebensbereiche [leef areas] en die beweerde Eigengesetzlichkeit [outonomie] daarvan (vlg. bv. Weber 1972). Vir Welker sluit pluralisme se deelsisteme onder andere politiek, opvoedingsinstellings, die regstelsel en godsdiens in. Hierdie deelsisteme is funksioneel gedifferensieer, neem dus namens die hele samelewing sekere onontbeerlike funksies waar, en is gevolglik meer stabiel as assosiasies (Welker 2002:23). Betreklik vaste simboliese en institusionele vorms verseker dat die deelsisteme hul take verrig, alhoewel ook hierdie vorme deurentyd deur die mense in die samelewing wat daaraan onderworpe is verander word.

Die onderskeide binne en tussen assosiasies en deelsisteme is vir Welker een van die grondliggende voorvereistes vir die funksionering van pluralisme se magskringloop (Welker 1995:17). Welker wys daarop dat hierdie onderskeide die mag binne 'n samelewing versprei en terselfdertyd deur destabilisering en verandering verdere differensiëring bevorder. Hy gee toe dat die beskerming en bevordering van verskille nie eenvoudig is nie en meen dat 'n pluralistiese samelewing deur 'n spesifieke dissipline gekenmerk behoort te word. Assosiasies en deelsisteme moet met oortuiging die etos van hul onderskeie groeperinge sowél as die oopheid vir gesprek en verandering van opinie bevorder (Welker 1995:19). Vir Welker is heterogeniteit, verandering, herposisionering, die verspreiding van mag en spesialisasie van kernbelang vir die magskringloop van pluralisme.

Pluralisme is vir Welker egter meer as bloot 'n tegniese organisering van 'n samelewing. Tesame met die oproep na voortdurende heterogenisering en herposisionering, vereis pluralisme eenstemmigheid oor die beginsels en vorme wat hierdie prosesse moontlikmaak. Pluralisme handel dus oor 'die verbinding én onderhouding van verskille, die moontlikmaak én ondersteuning van die verskeidenheid van vorme' (Welker 2002:229). Pluralisme is nie bloot die institusionele komplement van individualisme nie. Dit is ten diepste 'n 'gemeenskap van gemeenskappe' (Welker 1995:14) waarbinne interaksie tussen dié gemeenskappe noodsaaklik is vir die funksionering van die samelewing (Welker 2002:229).

\section{Bedreigings vir pluralisme se magskringloop}

Dit is dalk reeds duidelik dat pluralisme'n betreklik kwesbare samelewingsvorm is. In sy beskrywing van pluralisme wys Welker daarop dat die kwesbaarheid van pluralisme veral daarin lê dat van die gevaarlikste bedreigings juis binne die magskringloop en struktuur daarvan lê.

Wanneer deelsisteme byvoorbeeld deur populisme gedryf begin word, soos die geval in die politiek of media kan wees, word die heterogeniteit van 'n pluralistiese samelewing bedreig (Welker 2002:231). Volgens Welker is populistiese deelsisteme 'n vorm van sisteempaternalisme en lê die gevaar veral daarin dat dit assosiasies sou kon onderdruk, 
koöpteer en in sekere gevalle selfs assimileer. 'n Tweede gevaar wat binne die pluralistiese magskringloop opgesluit lê, is sogenaamde konformerende assosiasies (Welker 2002:232). Wanneer assosiasies weens sistemiese of ander redes hul eiesoortigheid begin onderspeel, word die magskringloop bedreig. Die gevaar is dan dat die bronne wat die magskringloop voed op hierdie wyse gedeaktiveer word.

Ook die struktuur van 'n pluralistiese samelewing kan geboorte gee aan sekere bedreigings (Welker 2002:233). Terwyl die funksionele differensiasie van die pluralistiese magskringloop sisteme en assosiasies van mekaar afgrens, ten einde mag so wyd moontlik te versprei, kan hierdie afgrensing ook onbedoelde negatiewe gevolge hê. Dit kan byvoorbeeld lei tot 'n Eigengesetzlichkeit [outonomie] van hierdie sisteme en assosiasies, sodat die onderskeie groeperinge óf nie bereid óf nie daartoe in staat is om met mekaar te interakteer nie. In hierdie opsig is dit nodig om daarop te let dat, volgens Welker, die heterogeniteit van 'n pluralistiese samelewing nie impliseer dat diskoerse oor oorkoepelende temas of selfs gedeelde doelstellings nie moontlik is nie. Inteendeel, vir die voortdurende herposisionering en verbetering van die kwaliteit van saambestaan van die individue en groepe binne 'n spesifieke gebied is sulke oorkoepelende temas en doelstellings noodsaaklik. Vir Welker (2002:238) is die aanname en verdediging van die onvervreembare menswaardigheid van alle persone een so 'n oorkoepelende tema.

Samevattend kan dus gesê word dat die magskringloop van pluralisme vir Welker afhanklik is van sisteme en assosiasies wat mag versprei. Hierdie vorme van veelvoud behoort in dié sin ook bereid tot kommunikasie te wees, veral rakende morele kwessies. Vir Welker is die onvervreembare menswaardigheid van alle persone een van die belangrikste morele kwessies in terme waarvan kommunikasie tussen sisteme moet plaasvind.

\section{Huber en pluralisme Pluralisme se samelewingsfere}

Wolfgang Huber benader die beskrywing van pluralisme vanuit 'n ander hoek as Welker, naamlik vanuit die struktuur daarvan. Hy beskou pluralisme, soos Welker, nie as 'n statiese of selfs stabiele samelewingsordening nie, maar as 'n samelewensordening wat ditself deurlopend herposisioneer. Dit is ook waarom Huber van die term 'pluralisering' eerder as bloot 'pluralisme' gebruikmaak.

Huber (1994) fokus sy beskrywing van die pluralisering van moderne samelewings op die ontwikkeling van vier Referenzbereichen, oftewel samelewingsfere, in sulke samelewings. Vir hom is die onderskeid tussen polis [stad] en oikos [huis] in die Griekse stadstate die eerste stap in die uiteindelike ontwikkeling van vier samelewingsfere. Hierdie twee-deling word tydens die Romeinse Antieke behou en eers die kerk se toetrede tot die samelewing verander dié twee-deling. In die Romeinse Ryk word die kerk van die huis onderskei, totdat die kerk as onderskeibare grootheid invloed op beide die private en politieke sfeer uitoefen. Dit is hierdie ontwikkeling wat uiteindelik aanleiding gee tot die invloedryke leer van die drie stande: die politia [politiek], oeconomia [ekonomie] en die ecclesia [gemeenskap].

Die Italiaanse Renaissance, Spaanse laat-skolastiek en die Reformasie inisieer prosesse wat hierdie drie-deling onherroeplik sou verander (Huber 1996:228-230). Die ekonomie word van die huis geskei om tot 'n verdere grootheid te ontwikkel. Bloedige oorloë lei in dié tyd tot selfs 'n dieper skeiding tussen die kerk en die politiek: die regstelsel en die gesag van die staat word geskei van godsdienstige legitimering (Huber 1990:34). Volgens Huber lei die skeiding van godsdiens en politiek uiteindelik tot 'n rasionalisering van die samelewingstruktuur: die natuurwetenskappe geniet toenemend voorrang, ekonomiese prosesse word deur 'n sogenaamde rasionele kapitalisme gestuur en die staat word as rasionele reguleerder van individuele gedrag gevorm.

Sodoende ontstaan volgens Huber 'n samelewing met oorwegend vier samelewingsfere, naamlik 'n politieke sfeer, 'n ekonomiese sfeer en sfere vir onafhanklike meningsvorming (later die burgerlike samelewing) en interkulturele kommunikasie (Huber 1994:167). Vir Huber gaan laasgenoemde sfeer om die gemeenskaplike bewussyn, gewete en wil van die burgers. Hierdie verdeling stem ooreen met ' $n$ aantal gesaghebbende interpretasies van moderne samelewings.

Vir Huber vorm hierdie vier samelewingsfere die basis vir verdere prosesse van pluralisering. Soos Welker, meen Huber egter ook dat pluralisme en pluralisering veel meer as 'n tegniese proses is. Ook Huber meen dat sekere gedeelde oortuigings noodsaaklik is vir die pluralisering van enige samelewing. Hy stel dan ook sulke beginsels voor, naamlik die afwysing van geweld, respek vir ander se menswaardigheid en verdraagsaamheid (Huber 1991:669). Op grond hiervan stel Huber dan ook taamlik spesifieke pluraliseringsprosesse binne elkeen van die vier samelewingsfere voor (Huber 1994:168-172).

\section{Die pluralisering van pluralisme}

In 'n pluralistiese samelewing vervul die regstaat 'n belangrike rol in die politieke sfeer. Dit is die regstaat wat met die beskerming van basiese regte en die instel van regverdige beperkinge op vryheid dit moontlikmaak dat die samelewing se verskeidenheid op 'n konstruktiewe wyse bevorder en beskerm kan word. Huber meen dat die politieke sfeer verder sou kon pluraliseer deur desentralisasie van staatsmag, deur meer geleenthede vir betrokkenheid by besluitnemingsprosesse vir landsburgers moontlik te maak en 'n toenemend sterker oriëntasie aan menseregte.

In die ekonomiese sfeer sien Huber die moontlikheid vir die demokratisering van mag. Dit sou kon geskied deur onder andere breër deelname aan bestuurs- en besluitnemingsprosesse en die verspreiding van kapitaal. Op makro-ekonomiese vlak stel Huber voor dat die sogenaamde 
markmeganisme onderwerp word aan regulering vanuit ander samelewingsfere, ten einde tot 'n meer regverdige verdeling van hulpbronne by te dra. Hy meen dat onbeheersde onderwerping aan die mark tot 'n tipe individualisme sou kon lei wat die gemeenskapsvorme wat pluralisme in stand hou, teenwerk.

Die burgerlike samelewing moet, volgens Huber, toenemend leer hoe om die mag van die politieke en ekonomiese sfere te begrens en te herposisioneer. Te midde van noodwendige en noodsaaklike verskeidenheid binne die burgerlike samelewing is hierdie groeperinge ook verantwoordelik vir die inisieer en voer van gesprekke rakende beginsels op grond waarvan die samelewing as geheel sou kon funksioneer.

Huber verbind die burgerlike samelewing ten nouste met die sfeer van multikulturele kommunikasie. Verantwoordelike multikulturele kommunikasie vind 'n middeweg tussen 'n onrealistiese soeke na homogeniteit en 'n relativistiese opheffing van dialoog. Anders gestel, sou 'n mens kon sê dat hierdie sfeer te make het met die manier waarop landsburgers binne die raamwerk van die regstaat in staat en bereid is om vanuit hul partikuliere oortuigings by te dra tot die welstand van die samelewing as geheel.

Noudat ons oorsigtelik aan Welker en Huber se beskouings van pluralisme aandag kon skenk, word hierdie bydrae afgesluit met 'n oorweging van die bydrae wat dit sou kon lewer tot die gesprek oor Christelike etiek binne 'n pluralistiese Suid-Afrika.

\section{Suid-Afrikaanse pluralisme en Suid- Afrikaanse kerke}

Suid-Afrika verskil natuurlik baie van die konteks waarbinne Welker en Huber se beskrywings van pluralisme ontwikkel is. Die Suid-Afrikaanse demokrasie sal, volgens alle aanduidings, nog vir die afsienbare toekoms konsolideer (Misra-Dexter \& February 2010), armoede en ongelykheid bied reuse uitdagings vir ontwikkeling (UNDP 2010), prosesse van herorganisering is steeds in die burgerlike samelewing aan die gang (Robinson \& Friedman 2005) en konstruktiewe saambestaan te midde van historiese en ander verskille is vir baie Suid-Afrikaners nie vanselfsprekend nie. Tog sou elemente van Welker en Huber se konseptualisering van pluralisme betekenisvol kon wees vir 'n oorweging van die kerk se publieke rol in 'n land waar verskeidenheid bevorder en beskerm word en waar die welstand van die samelewing nou afhanklik is van hoe hierdie verskeidenheid hanteer word.

Aan die hand van Welker en Huber se konseptualiserings word vervolgens twee voorwaardes wat 'n publieke betrokkenheid van die kerk in 'n pluralistiese samelewing moontlik sou kon maak, ondersoek.

\section{Twee voorwaardes}

Uit die bespreking van beide Welker en Huber se sieninge van pluralisme is dit duidelik dat heterogeniteit een van die basiese kenmerke van ' $n$ pluralistiese samelewing is. Welker beskou heterogeniteit binne en tussen deelsisteme en assosiasies as van fundamentele belang vir die verspreiding en vloei van mag en hy waarsku teen die homogenisering wat populisme of sisteempaternalisme sou kon veroorsaak. Huber sluit konseptueel by Welker aan, maar lê veral klem op die voortgaande en gerigte heterogenisering (of pluralisering) van die verskillende samelewingsfere. Dit impliseer die bevordering en beskerming van die partikulariteit van groeperinge en individue binne so'n samelewing (vlg. Huber 1994:170). Die vermoë van individue om verantwoordelike burgers van ' $n$ pluralistiese samelewing te wees, word inderdaad sonder uitsondering bepaal deur die spesifieke bronne wat hul spesifieke interpretasiegemeenskappe voed.

Hierdie oortuiging sou met vrug op die moontlike rol van kerke in die Suid-Afrikaanse samelewing toegepas kon word. Dit blyk dan dat die uitdruklik Christelike oortuigings wat kerke se betrokkenheid dryf en vorm hulle juis kwalifiseer om tot die instandhouding en uitbouing van die samelewing se pluralisme by te dra (vgl. Welker 1995:18). 'n Deursigtige verbintenis met en verantwoording van Christelike bronne sou populisme en sisteempaternalisme teë kon werk. Anders gestel, sou 'n mens kon sê dat dit hul unieke motivering is wat aan kerke die vermoë gee om met assosiasies en die groter sisteme te interakteer (Küng 1993; Welker 1993a, 1993b). Op hierdie wyse dra hulle daartoe by dat mag versprei word en dat selfs die vloei van mag op 'n opbouende wyse sou kon plaasvind.

'n Eerste voorwaarde vir Suid-Afrikaanse kerke se publieke betrokkenheid in 'n pluralistiese samelewing sou dus die volgende kon wees: kerke het die verpligting om deursigtig en verantwoordbaar aan hul partikuliere bronne getrou te bly.

Hierdie getrouheid sou natuurlik op 'n aantal verskillende maniere uitgeoefen kon word. Dit sou byvoorbeeld daarop gemik kon wees om, bedoeld of selfs onbedoeld, vervreemding en isolasie te bring en 'n tipe heterogeniteit te bevorder wat nie tot voordeel van die samelewing as geheel is nie. Vanuit die bespreking van beide Welker en Huber se sieninge is dit egter duidelik dat pluralisme of pluralisering opsigself nie as doelstellings beskou word nie en dat ' $n$ konstruktiewe heterogeniteit bevorder moet word. Beide denkers lê daarop klem dat eenstemmigheid, of ten minste dialoog, oor die basiese beginsels ter wille waarvan 'n pluralistiese samelewing bestaan onontbeerlik is. Terwyl Welker respek vir elkeen se menswaardigheid as ' $n$ beginsel vir dié dialoog voorstel, stel Huber beginsels én prosesse voor wat volgens hom sekere gedeelde doelstellings tot uitdrukking sou kon bring.

Beide Welker en Huber se voorstelle gaan van die veronderstelling uit dat die kommunikasie tussen verskillende groeperinge deur oopheid vir gesprek, die oortuiging dat konsensus en samewerking moontlik is en die bereidheid om van posisie te verander, gekenmerk behoort te word (bv. Huber 1993; Welker 2002:257). Daarom sou ook 'n tweede voorwaarde geïdentifiseer kon word, naamlik dat 
publieke betrokkenheid van kerke deur ' $n$ oopheid vir dialoog en samewerking en die bereidheid tot herposisionering gekenmerk word.

So 'n voorwaarde sou natuurlik ietwat optimisties kon voorkom. Daar sou gevra kon word hoe so 'n dialoog dan enigsins moontlik kon wees. In Welker se bekende debat met Küng oor onder andere die ooroptimisme van Küng se Projekt Weltethos, kwalifiseer Welker sy siening van oopheid vir dialoog (Küng 1993, Welker 1993a en 1993b; kyk ook Küng 2008). Teenoor Küng stel hy dat dialoog noodsaaklik, maar nie noodwendig eenvoudig is nie en dat die partikulariteit van en respek vir verskillende bydraes en nie persepsies rakende gedeelde oortuigings nie die beginpunt vir dialoog in 'n pluralistiese samelewing is.

Huber se siening in hierdie verband stem tot ' $n$ groot mate met dié van Welker ooreen. Vir hom vorm die baie realistiese soeke na minimumvereistes [Minimalbedingungen] vir die konstruktiewe saambestaan van verskillende groeperinge die basis vir dialoog (Huber 1993:172). Hy meen wel dat sekere oorvleuelende etiese oorwegings [Überschneidungsbereiche] gevind sou kon word, maar beskou die oopheid om op grond van elkeen se partikulêre bronne na minimumvereistes vir saambestaan te soek as van groter belang (Huber 1993:180).

Op 'n teoretiese en selfs tot 'n sekere mate op 'n eksistensiële vlak sou hierdie voorbehoude vir kerke dalk moontlik kon wees. Daar is egter wel ten minste twee vrae gebore uit die Suid-Afrikaans konteks waarvoor Huber en Welker se werk oor pluralisme waarskynlik nie antwoorde kan gee nie. Hierdie vrae word in die konklusie van hierdie artikel bespreek.

\section{Slotsom}

Eerstens sou gevra kon word waar dialoog tussen die verskillende groeperinge binne die Suid-Afrikaanse konteks sou kon plaasvind. Post-apartheid Suid-Afrika word immers gekenmerk deur ' $n$ burgerlike samelewing wat breed, maar betreklik vlak is (Friedman 2010:121-124). Alhoewel daar meer persone in die Suid-Afrikaanse burgerlike samelewing as in die land se myne werksaam is (Swilling, Russel, Sokolowski \& Salamon 2004:112), is daar groot segmente van die samelewing wat nie die wil of geleentheid het om daaraan deel te neem nie. Neeta Mishra-Dexter en Judith February (2010:7) herinner ons daaraan dat persone wat sukkel om toegang tot werksgeleenthede, behuising en vervoer te kry en wat daarmee saam blootgestel is aan substandaard gesondheidsdienste, 'n tekort aan skoon drinkwater en onvoldoende opvoeding, noodwendig beperk sal word in hul deelname aan burgerlike samelewing.

Verder word die vorm van die Suid-Afrikaanse burgerlike samelewing steeds tot 'n redelike mate deur die land se geskiedenis bepaal. Diep skeidinge op grond van ras, etnisiteit, godsdiens en kultuur is steeds teenwoordig, soos ook 'n skeiding tussen groot gesondheids- en maatskaplike organisasies uit hoofsaaklik bevoorregte segmente van die samelewing met ' $n$ kapasiteit om dienste aan ' $n$ groot verskeidenheid groepe te lewer en ' $n$ groot hoeveelheid meer informele gemeenskapsgebaseerde organisasies wat dienste aan die armer segmente van die samelewing verskaf (Swilling, Russel, Sokolowski \& Salamon 2004:123-124). Alhoewel geen praktiese voorstelle aangebied word nie, is dit uit Welker en Huber se analises duidelik dat meer ruimtes vir interaksie binne die Suid-Afrikaanse samelewing geskep sou moes word ten einde pluralisme hier sinvol dit laat plaasvind.

Tweedens kan daar gevra word wie op dié oortuigde wyse Christelik aan die herposisionerings van die Suid-Afrikaanse pluralisme sou kon deelneem. Welker en Huber skryf in 'n konteks waar Duitse Christene feitlik geheel en al deur twee groot kerke verteenwoordig word. Om die bevordering van pluraliteit binne dié konteks te bevorder, sou uit die aard van die saak sin maak. Die Suid-Afrikaanse kerklike toneel lyk natuurlik heelwat anders.

Alhoewel bykans $80 \%$ van alle Suid-Afrikaners hulself as Christene beskou, behoort rondom $25 \%$ van dié Christene aan losweg-geaffilieerde Afrika-geïnisieerde kerke. Die grootste hoofstroomkerke is die Rooms-Katolieke, Gereformeerde en Metodiste gemeenskappe, elk met maar 9\% van SuidAfrikaanse Christene as hul lidmate (SSA 2001). Pluralisering binne hierdie segment van die burgerlike samelewing is dus 'n gegewe en die uitdaging tot koördinering is veel groter as in sommige ander lande. Dit vereis vindingryke en na alle waarskynlikheid eklektiese prosesse van kommunikasie op 'n kleiner skaal as dié in Duitsland. Daarmee saam kompliseer die huidige polemiek tussen die Suid-Afrikaanse Raad van Kerke, die National Interfaith Leadership Council en die National Religious Leaders' Forum hierdie stand van sake verder.

Uit hierdie Suid-Afrikaanse oorweging van Michael Welker en Wolfgang Huber se werk oor pluralisme wil dit dus blyk asof Suid-Afrikaanse kerke tog 'n publieke rol het om te speel, mits 'n balans tussen partikulariteit en oopheid gevind kan word en die ruimtes vir en deelnemers aan hierdie gesprekke op vindingryke maniere uitgeklaar en uitgebrei word.

\section{Literatuurverwysings}

Aron, J., Kahn B. \& Kingdon, G., 2009, South African Economic Policy under Democracy [Suid-Afrikaanse ekonomiese beleid onder demokrasie], Oxford University Press, Oxford. doi:10.1093/acprof:0so/9780199551460.001.0001

Bhorat, H. \& Kanbur, R. (eds.), 2006, Poverty and Policy in Post-apartheid South Africa [Armoede en beleid in post-apartheid Suid-Afrika], HSRC Press, Cape Town.

Chidester, D., Dexter, P. \& James, W., 2003, What Holds Us Together. Social Cohesion in South Africa [Wat on saam hou. Sosiale kohesie in Suid-Afrika], Human Sciences Research Council, Pretoria.

Deng, F.M. (ed.), 2010, Self-determination and National Unity. A Challenge for Africa [Selfbeslissing en nasionale eenheid. ' $n$ Uitdaging vir Afrika], Africa World Press, Trenton, NJ.

Du Toit, B., 2000, God? Geloof in 'n postmoderne tyd, CLF, Bloemfontein.

Friedman, S., 2010, 'Beneath the Surface: Civil Society and Democracy after Polokwane' [Onder die oppervlak: Siviele samelewing en demokrasie na Polokwane [Onder die oppervlak: Siviele samelewing en demokrasie na Way is South Africa Going?, pp. 117-39, Idasa, Johannesburg.

Gutteridge, W. (ed.), 1995, South Africa. From Apartheid to National Unity, 19811994, [Suid-Afrika. Van apartheid na nasionale eenheid], Dartmouth, Aldershot, UK.

Huber, W., 1990, 'Der Protestantismus und die Ambivalenz der Moderne' [Protestantisme en die dubbelsinnigheid van die moderniteit], J. Moltmann (red.), Religion der Freiheit. Protestantismus in der Moderne, pp. 29-65, Kaiser, München.
(red.), Religion 
Huber, W. \& Graf, F.W., 1991, 'Konfessorische Freiheit oder relativistische Offenheit? Ein theologisches Streitgespräch' [Belydende vryheid of relativistiese openheid? ' $n$ Teologiese dispuut], Evangelische Kommentare 24, 669-673.

Huber, W., 1993, Die tägliche Gewalt. Gegen den Ausverkauf der Menschenwürde [Die daaglikse geweld. Teen die verkoop van menswaardigheid], Herder, Freiburg im Breisgau.

Huber, W., 1994, 'Öffentliche Kirche in pluralen Öffentlichkeiten' [Openbare kerk in pluralistiese samelewing], Evangelische Theologie, 54(2), 157-180.

Huber, W., 1996, Gerechtigkeit und Recht [Geregtigheid en die reg], Chr. Kaiser/ Gütersloher Verlagshaus, Gütersloh.

Koopman, N.N. \& Vosloo, R.R., 2002, Die ligtheid van die lig. Morele oriëntasie in 'n postmoderne tyd, Lux Verbi, Wellington.

Küng, H., 1993, 'Nicht gutgemeint - deshalb ein Fehlschlag. Zu Michael Welkers Reaktion auf "Projekt Weltethos"' [Sonder goeie bedoelings - so 'n mislukking. Michael Welker se antwoord op 'Projek Wêreldetiek'], Evangelische Kommentare 27, 486-489.

Küng, H., 2008, Global Ethic Foundation. History and Aims [Globale etiese stigting. Geskiedenis en doelwitte], besigtig 21 Januarie 2011, van http://www.weltethos. org/dat-english/01-history.htm

Luhmann, N., 1971, 'Moderne Systemtheorien als Form gesamtgesellschaftlicher Analyse'[Moderne stelselteorieë as ' $n$ vorm van algemene sosiale analise], in $\mathrm{N}$. Luhmann \& J. Habermas (reds.), Theorie der Gesellschaft oder Sozialtechnologie, pp. 7-24, Suhrkamp Verlag, Frankfurt a.M.

Luhmann, N., 1982, The differentiation of society [Die differensiasie van die samelewing], transl. S. Holmes \& C. Larmore, Columbia University Press, New York, NY

Mandela, N.R., 1994, Inaugural Address, May 10, 1994 [Intreerede], viewed 10 Februarie 2011, from www.info.gov.za/speeches/1994/990319514p1006.htm.

Misra-Dexter, N. \& February, J. (eds.), 2010, Testing Democracy: Which Way is South Africa Going? [Toets demokrasie: Waarheen gaan Suid-Afrika?], Idasa, Johannesburg.

Niemandt, C.J.P., 2007, Nuwe drome vir nuwe werklikhede. Geloofsgemeenskappe in pas met 'n postmoderne wêreld, Lux Verbi.BM, Wellington.

Robinson, M. \& Friedman, S., 2005, Civil Society, Democratisation and Foreign Aid in Africa [Burgerlike samelewing, demokratisasie en buitelandse hulp in Afrika], Institute of Development Studies, Brighton, UK.
Suid-Afrikaanse Regering, 1996, Grondwet van die Republiek van Suid-Afrika, SuidAfrikaanse Regering, Kaapstad.

Swilling, M., Russel B., Sokolowski, S.W. \& Salamon, L.M., 2004, 'South Africa' [SuidAfrika], Global Civil Society (Volume 2). Dimensions of the Nonprofit Sector, pp. 110-125, Kumarian, Bloomfield, CT.

Seekings, J. \& Nattrass, N., 2006, Class, Race and Inequality in South Africa [Klas, ras en ongelykheid in Sui-Afrika], University of KwaZulu-Natal Press, Scottsville.

Statistics South Africa, 2001, Census 2001, viewed 10 Februarie 2011, from http:// www.statssa.gov.za/census01/html/C2001Interactive.asp

Terreblanche, S.J., 2002, A History of Inequality in South Africa, 1652-2002 ['n Geskiedenis van ongelykheid in Suid-Afrika], University of Natal Press, Pietermaritzburg.

Tutu, D.M., 1996, The Rainbow People of God. The Making of a Peaceful Revolution [Die reënboog volk van God. Die skepping van 'n vreedsame revolusie], Doubleday, New York, NY.

UNDP, 2010, Human Development Report 2010, viewed 10 Februarie 2011, from http://hdr.undp.org/en/reports/global/hdr2010/chapters/en

Weber, M., 1972, Wirtschaft und Gesellschaft. Grundriss der verstehenden Soziologie (5. Aufl.) [Ekonomie en die samelewing. 'n Vloerplan vir interpretatiewe sosiologie], Mohr Siebeck, Tübingen.

Welker, M., 1993a, 'Gutgemeint - aber ein Fehlschlag. Hans Küngs "Projekt Weltethos" [Goed bedoel - maar 'n mislukking. Hans Küng se 'Projek Wêreldetiek'], Evangelische Kommentare 26, 354-356.

Welker, M., 1993b, 'Autoritäre Religion. Replik auf Hans Küng' [Outoritêre godsdiens. Antwoord op Hans Küng], Evangelische Kommentare 26, 528-529.

Welker, M., 1995, Kirche im Pluralismus [Pluralisme in die kerk], Kaiser Tachenbücher, Gütersloh.

Welker, M., 2002, 'Wovon der freiheitliche Staat lebt. Die Quellen politischer Loyalität im spätmodernen Pluralismus', [Waarvan die liberale stad lewe. Die bronne van politiese lojaliteit in die laat-moderne pluralisme], $\mathrm{H} . \mathrm{R}$. Reuter, $\mathrm{H}$. BedfordPlutschrift für Wolfgang Huber zum 60. Geburtstag, pp. 225-242, Kaiser, Gütersloher Verl. Haus, 